\title{
KNOWLEDGE REGARDING HIV/AIDS AMONG THE ADULT POPULATION IN A RURAL COMMUNITY
}

\author{
Ara ${ }^{1}$, Uddin $\mathrm{MN}^{2}$, Wahab $\mathrm{MA}^{3}$, Khondker $\mathrm{L}^{4}$, Khan $\mathrm{MSI}^{5}$
}

\begin{abstract}
Introduction: The consequences of HIV/AIDS are alarming. It causes not only loss of live but also social and economic disruption. Being deadly disease, HIV/AIDS has become an important issue of recent times throughout the world. To date, little is known about awareness of HIV/AIDS in Bangladesh.
\end{abstract}

Objectives: To assess the level of knowledge regarding Human Immunodeficiency Virus (HIV)/ Acquired Immune Deficiency Syndrom (AIDS) among the adult population of a rural community.

Place and Period of study: the study was done at 'Tepir Bari, Saitalia, Tengra' village under 'Teli Hati' union of Shreepur Upazilla in Gazipur district during the study period of 27 March 2010 to 31 April 2011.

Materials and Methods: This cross sectional type of study was conducted with 360 respondents. Semi structured interview schedule was used for collection of information and sampling technique was 'selective cluster sampling'.

Results: Among the total 360 respondents $92.5 \%$ respondents had knowledge regarding HIV/AIDS and $7.50 \%$ had no knowledge about HIV/AIDS. The respondents who were familiar with the term of HIV/AIDS, $86.79 \%$ had gathered information from mass media. Most of respondents $83.78 \%$ consider that sexual route is the principal means of spreading HIV/AIDS.
According to them the other most common ways of spreading HIV/AIDS were sharing same needle (49.55\%), through blood and blood products $(43.24 \%)$, vertical transmission $19.21 \%$. Among 333 respondents, $64.72 \%$ considered that the top most high risk group was commercial sex workers. $55 \%$ considered individuals sharing same needle, $40.2 \%$ thought individuals having illegal relationships, 23.33\% considered unsafe blood recipients, $11.11 \%$ considered drivers, $10.28 \%$ considered frequent traveler and $15.83 \%$ respondents had no knowledge about high risk groups. Regarding the knowledge about preventing HIV/AIDS majority of respondents (64.44\%) considered that the safe sexual behavior is the main way to prevent HIV/AIDS. $32.22 \%$ respondents considered using unshared needle, $28.89 \%$ respondents thought health education regarding AIDS, 26.44\% individuals thought proper maintenance of religious values, $21.44 \%$ considered proper screening where as $16.11 \%$ respondents had no knowledge about preventive measures.

Conclusion: Among the study subjects majority of the respondents had knowledge regarding HIV/AIDS and few had no knowledge and they need information and health education.

Key-Words: Knowledge regarding HIV/AIDS, transmission of HIV/AIDS, prevention of HIV/AIDS.

1. Dr. Rowshan Ara, MBBS, MPH, Mphil (PSM), Asst Prof, Dept of Community Medicine, DMC, Dhaka. 2. Maj Gen Md Nasir Uddin, MBBS, MPH, MPhil (PSM), Commandant, AFMC, Dhaka Cantt. 3. Maj Md Abdul Wahab, MBBS, MD, Asst Prof, Dept of Biochemistry, AFMC, Dhaka Cantt. 4. Dr. Lubna Khondker, MBBS, MPH, DDV, MCPS, FCPS (Dermatology and Venereology), Asst Prof of Dermatology and Venereology, BSMMU, Dhaka. 5. Lt Col Md Shirajul Islam Khan, MBBS, DDV, MCPS (Dermatology and Venereology), Graded Spl in Dermatology and Venereology, AFMI, Dhaka Cantt. 


\section{Introduction}

HIV/AIDS is a global problem. At the end of 2009, 33.3 million people were estimated to be living with $\mathrm{HIV}^{1}$. An estimated 2.6 million people newly became infected with HIV in 2009 and 1.8 million died. In Bangladesh the first case was detected in 1989. Since then about 6300 people were infected by 2009 and the number is increasing day by day. The actual number of people living with HIV and AIDS may be around 7,500 in Bangladesh ${ }^{2}$.

The risk factors include low level of knowledge on HIV and AIDS $^{3,4}$ low use of condoms ${ }^{3,5,6,7}$ multiple sexual partners ${ }^{4,7}$ high incidence of sexually transmitted infections (STIs) ${ }^{3,4}$ poor blood safety ${ }^{4,8}$ risk of transmission from returned expatriates ${ }^{\mathbf{4 , 6 , 9}}$ and the presence of HIV in neighboring countries, such as India and $\mathrm{Nepa}^{\mathbf{3 , 6 , 4 , 9}}$ with which Bangladesh shares not only cultural similarities but also a porous border. A total of 240 AIDS cases were detected so far of which 109 have already $\operatorname{died}^{10}$. An estimated 11.8 million young people worldwide (7.3 million young women and 4.5 million young men), aged between 15 to 24 years are living with HIV/AIDS. AIDS has killed more than 25 million people in the world since it was first recognized in 1981, making it one of the most destructive epidemics in recorded history ${ }^{11}$. Recent works in the field of HIV and AIDS prevention and control in Bangladesh has highlighted the impending HIV epidemic in the country since the prevalence of HIV is rising among injecting drug-users (IDUs) with a grave risk of transmission to other groups in society ${ }^{12}$.

AIDS indeed is a terribly dangerous disease found almost everywhere in human society ${ }^{\mathbf{1 3}}$. People having AIDS are always under the threat of death and the disease is caused by the Human Immunodeficiency Virus, usually known as HIV. HIV is a kind of virus which makes the human body almost incapable of fighting any kind of infection ${ }^{14}$. The most advanced stage of HIV infection is
Acquired Immune Deficiency Syndrome (AIDS) which takes about 10-15 years to develop and this is the end stage of life. The anti retroviral drugs can slow the progress but cannot cure the person. No vaccine against HIV is yet available ${ }^{\mathbf{1 5}}$. So, knowledge about HIV and its prevention is the only possible way to stay safe.

The consequences of HIV/AIDS are alarming. It causes not only loss of lives but also social and economic disruption. Being a deadly disease, HIV/AIDS has become an important issue of recent times throughout the world ${ }^{\mathbf{1 6}}$. To date, little is known about awareness of HIV/AIDS in Bangladesh. So our study will help the Government and Non Government organizations to take necessary strategic interventions to improve the knowledge and outlook of AIDS in rural people. This will help them to live a disease-free healthy life.

\section{Materials and Methods}

This is a descriptive type of cross sectional study which was conducted at TepirBari, Saitalia, Tengra Village under ward no-08 and 09 of Telihati union of Shreepur Upazilla in Gazipur District. In this study the study population was adult rural people of both sexes between the age of 18-60 years and the study was carried out between 27 March 2010 to 31 April 2011. The sample size was 360 of rural population which was determined conveniently. Semi-structured interview schedule was used for collection of information and the sampling technique was selective cluster sampling.

Data collection and filling up gaps as well as data review were done carefully. Collected data were checked, verified and edited for consistency. The result was analyzed using SPSS version 12 in computer. 


\section{Results}

Age distribution of respondents reveals that minimum and maximum age were 18 and 60 years respectively. The table shows that most of the respondents (26.94\%) were in the age group 30-35 years where the lowest numbers of respondents (1.94\%) were in 54-59 years age group, $20.27 \%$ were in $24-29$ year age group (Table-I).

Table-I: Age distribution of respondents

\begin{tabular}{|l|l|l|}
\hline Age in year & Frequency & Percentage \\
\hline $18-23$ & 69 & 19.17 \\
\hline $24-29$ & 73 & 20.27 \\
\hline $30-35$ & 97 & 26.94 \\
\hline $36-41$ & 49 & 13.61 \\
\hline $42-47$ & 33 & 9.17 \\
\hline $48-53$ & 24 & 6.67 \\
\hline $54-59$ & 07 & 1.94 \\
\hline$\geq 60$ & 08 & 2.22 \\
\hline Total & 360 & 100 \\
\hline
\end{tabular}

The mean age of respondents was 33.23 years with SD of \pm 9.85 years.

Fig-1 shows that out of 360 respondents female were $52.5 \%$ and male were $47.5 \%$.

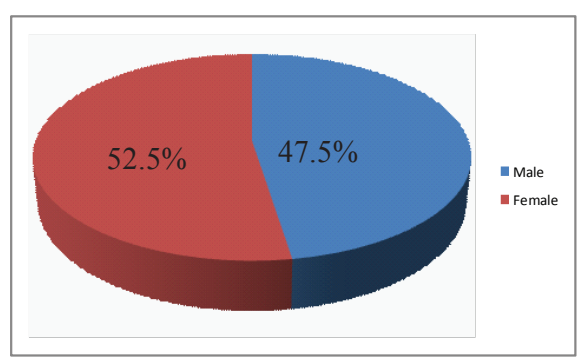

Fig-1: Sex distribution of respondents

Fig-2 shows that, out of 360 respondents $73.61 \%$ (265) respondents were institutionalized and $11.94 \%$ (43) were non institutionalized where as $14.44 \%(52)$ respondents were illiterate.

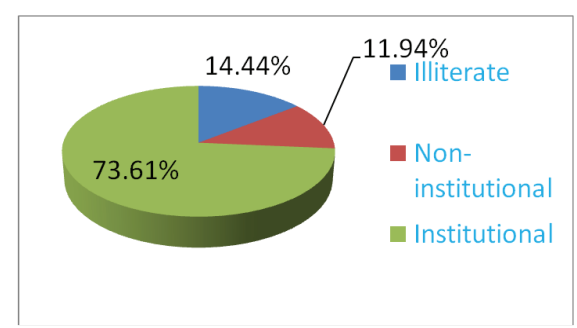

Fig-2: Educational status of respondents
Regarding occupational distribution Fig-3 shows that, out of 360 respondents $46.10 \%$ respondents were housewife, $17.50 \%$ were farmer, $14.17 \%$ were businessmen, $7.22 \%$ were labourer, $6.67 \%$ were service holder and $2.50 \%$ were unemployed.

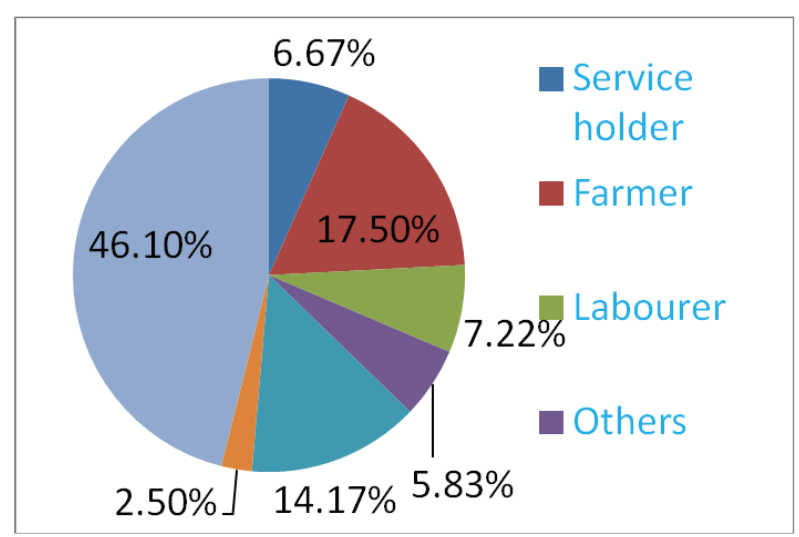

Fig-3: Distribution of respondents according to their occupation.

Among the total 360 respondents $92.5 \%$ respondents have knowledge regarding HIV/AIDS and $7.50 \%$ have no knowledge about HIV/AIDS. Among those having knowledge regarding HIV/AIDS, $48.95 \%$ were male and $51.05 \%$ were female. Among those having no knowledge regarding HIV/AIDS $29.63 \%$ was male and $70.37 \%$ were female.

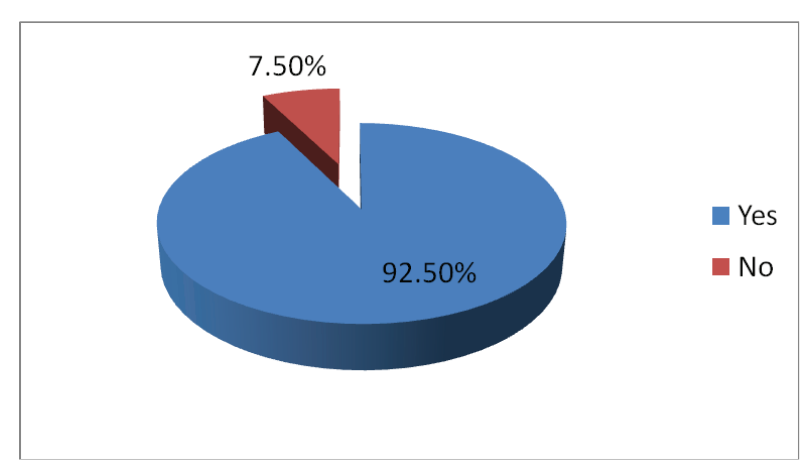

Fig-4: Respondents knowledge about HIV/AIDS 
Fig-5 shows that the respondents who were familiar with the term of HIV/AIDS, $86.79 \%$ had gathered information from mass media. The other sources were health worker $(16.51 \%)$, friends $(24.02 \%)$, Spouse $(2.10 \%)$ and $5.71 \%$ were other sources (here multiple responses present.

\section{$86.79 \%$}

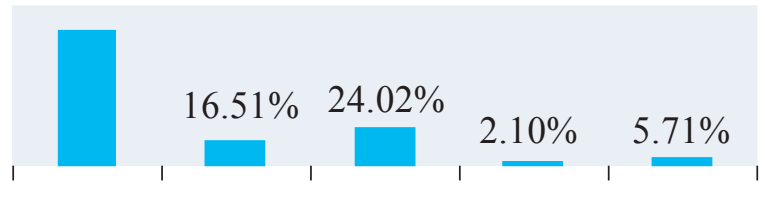

Mass Health Friends Spouse Others media worker

Fig-5: Respondents knowledge regarding source of information about HIV/AIDS

Table-II shows that most of respondents (83.78\%) consider that sexual route is the principal means of spreading HIV/AIDS. Other most common way of spreading that they consider were sharing same needle $(49.55 \%)$, Blood and blood products (43.24\%), Vertical transmission (19.21\%), 18.32\% persons had no knowledge about mode of transmission.

Table-II: Respondents knowledge regarding modes of transmission of HIV/AIDS ( $n=360)$

\begin{tabular}{|l|l|l|}
\hline Mode of transmission & Frequency & Percentage \\
\hline Sexual route & 279 & 83.78 \\
\hline Sharing same needle & 165 & 49.55 \\
\hline Blood and blood products & 144 & 43.24 \\
\hline Vertical transmission & 64 & 19.21 \\
\hline $\begin{array}{l}\text { Having no knowledge } \\
\text { about mode of transmission }\end{array}$ & 61 & 18.32 \\
\hline
\end{tabular}

$\mathrm{n}=360$ (Multiple response present)

Fig- 6 shows that among 360 respondents, $64.72 \%$ considered that the top most high risk group was commercial sex workers. 55\% considered individual sharing same needle, $40.2 \%$ thought individuals having illegal relationships, $23.33 \%$ considered them to be unsafe blood recipients, $11.11 \%$ considered drivers, $10.28 \%$ considered frequent travellers, $15.83 \%$ respondents had no knowledge about high risk groups(here multiple response present).

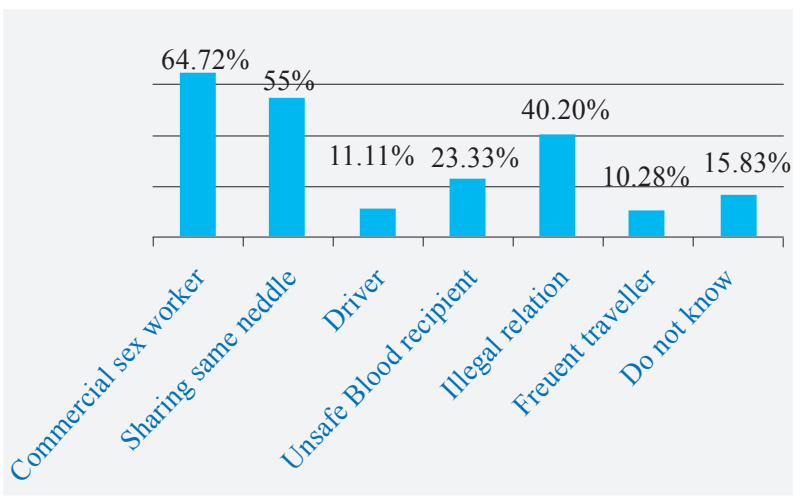

Fig-6: Concept among the respondents about high risk group of HIV/AIDS.

Table-III shows that majority of respondents $(64.44 \%)$ considered that the safe sexual behavior is the main way to prevent HIV/AIDS.32.22\% respondents considered it to be using unshared needle, $28.89 \%$ respondents thought health education regarding AIDS, $26.44 \%$ individuals thought proper maintenance of religious values, $21.44 \%$ considered proper screening where $16.11 \%$ respondents had no knowledge about preventive measures.

Table-III: Respondents knowledge regarding prevention of HIV/AIDS.

\begin{tabular}{|c|c|c|}
\hline Preventive measure & Frequency & Percentage \\
\hline Safe sexual behaviour & 232 & 64.44 \\
\hline Using unshared needle & 116 & 32.22 \\
\hline Health education & 104 & 28.89 \\
\hline $\begin{array}{c}\text { Proper maintenance } \\
\text { of religious values }\end{array}$ & 97 & 26.44 \\
\hline Proper screening & 79 & 21.44 \\
\hline Having no knowledge & 58 & 16.11 \\
\hline
\end{tabular}

$\mathrm{n}=333$ (Multiple response present) 
Fig-7 shows that among 360 respondents $61.67 \%$ were sympathetic to AIDS patients where as $30 \%$ respondents had negative attitude towards AIDS patients and $8.33 \%$ respondents were reluctant to give comments.

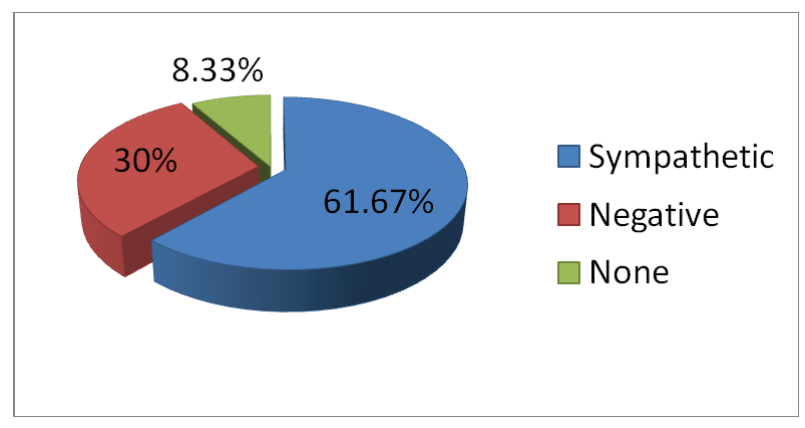

Fig-7: Attitude of respondents towards HIV/AIDS patients

\section{Discussion}

In our cross sectional study, the aim was to evaluate the level of knowledge regarding HIV/AIDS among the adult population in a selected rural community at Sreepur Upazilla of Gazipur district. In this study, different levels of knowledge of adult population regarding HIV/AIDS were considered. Inspite of being an observational study, this may provide an excellent means to take appropriate interventions in preventing the spread of HIV/AIDS in Bangladesh.

There was a distinct pattern in the distribution of the respondents in age category. In this study the age of the respondents ranged from 18 to 60 years .The mean age of the male respondents was 35.91 years with standard deviation of 11.46 years. For female, most respondents were between 30-35 years with mean age of 30.71 years and $\mathrm{SD} \pm 8.24$ years. In a study conducted by Rahman MM, Kabir M, Shahidullah M, mean age of respondents was $33.4 \pm 7.4$ years with a range of 20 to 55 years ${ }^{13}$. Another study was conducted by Jiajian Cher, Chen
Shengi and Minja Kim among adults aged between 15 - 49 years $^{6}$. So, in comparison with national and international studies, the age selection of our study was quiet justifiable because this age range is the age of active sexual life and the knowledge of this age group can give an overall idea about the knowledge of at risk population.

Regarding sex distribution, female respondents were $52.5 \%$ and the males were $47.5 \%$. Sex distribution was equal in the study conducted by Rahman et $\mathrm{al}^{13}$. In the study by Jiajian Cher, Chen Shengi and Minja Kim $52 \%$ were male and $48 \%$ were female ${ }^{6}$. We had more female respondents because we visited the houses during working hour, when men were not at home.

In our study $85.56 \%$ of the respondents were literate and illiterate were $14.44 \%$. Among the literate $73.62 \%$ were institutional and $11.94 \%$ were non institutional. An almost similar result was revealed by a study conducted by Rahman et al where $16 \%$ were illiterate and $25 \%$ had primary level of education 13 . This result is almost similar to our study result.

Among the respondents $46.10 \%$ were housewives, next to it were farmers $(17.5 \%)$, businessmen (14.17\%), service holders $6.67 \%$, labourer (7.22\%), unemployed $(2.50 \%)$ and others were $5.83 \%$. A study conducted by Rahman M M, Kabir M \& Shahidullah M showed that $1 / 3$ of the respondents were labourers, $28 \%$ small traders, $19 \%$ businessmen \& $17 \%$ were service holders ${ }^{13}$. In a study by Prosannajid Sarker $68 \%$ people were found to be having permanent employment ${ }^{12}$. The occupation distribution of our study population do not coincide with these results. The geographic variation affecting the occupation of people may be the cause of this disparity.

In our study, among the $92.5 \%$ respondents who were familiar with the term of HIV/AIDS, $86.79 \%$ had gathered information from mass media. The other sources were health workers (16.51\%), friends 
(24.02\%), Spouse (2.10\%) and others 5.71\%. A study done by Moshiur Rahman showed that , $8.4 \%$ of people learnt about HIV/AIDS from health workers, $8.1 \%$ learnt from newspapers/ magazines, $4.8 \%$ people learnt from posters ${ }^{16}$. Another study done by Rahman et al showed that $41.4 \%$ men gained idea about HIV/AIDS from radio, $66.4 \%$ from TV , 26.8\% from newspapers, $33 \%$ from health workers and 30.4 $\%$ from friends ${ }^{13}$. A study conducted by Mohammad Shafiqur Rahman and Mohammad Lutfur Rahman showed that $77.1 \%$ of female TV watchers and $67 \%$ of male daily radio listeners were concerned about AIDS $^{9}$. A study conducted by O.F. Deji and Enueswemba based on "Assessment of the awareness of HIV/AIDS among the rural dwellers in its zone of ocean state, Nigeria' on 2005 revealed that $67 \%$ respondents was aware of HIV/AIDS ${ }^{15}$. Radio (36.3\%) and television (14.1\%) were the most common source of awareness. All these results were similar to our results and they reveal that mass media is the main source of knowledge for most people.

In our study, $83.78 \%$ of respondents consider that sexual route is the principal means of spreading HIV/AIDS. Other most common ways of spreading according to them were sharing same needle $(49.55 \%)$, through blood and blood products (43.24\%), and vertical transmission (19.21\%). Persons having no knowledge about mode of transmission were of $18.32 \%$. A study showed that $27 \%$ respondents did not know about the mode of transmission of AIDS. $83 \%$ of the respondents mentioned that AIDS may be transmitted through sexual intercourse by people who habitually have multiple sexual partners. This is followed by transmission through unscreened blood transfusion $(64 \%)$, sharing needle for drug use $(60 \%)$, sexual intercourse without condom (39\%) and homosexuality $^{8}(32 \%)$. Another study conducted by Mizanur Rahman and M Kabir shows that AIDS may transmit through sexual intercourse with affected person $(36.9 \%)$ and through blood ${ }^{13}(14.3 \%)$. A study done by Moshiur Rahman shows that people believe that HIV transmits mostly through uncontrolled sexual relationship with multiple partners then through blood (32.8\%) and through same injection $22 \%{ }^{16}$.
A study conducted by Prosannajid Sarkar in 2009 based on information and knowledge about HIV/AIDS ${ }^{14}$. Bangladesh context revealed that, $48 \%$ of rural population knew blood transfusion as the route of transmission of HIV/AIDS and 34\% knew it to be through unsterilized needle or syringe. So, our study population had a good knowledge about the transmission route which is almost similar to the findings of other studies.

Regarding preventive measures of HIV/AIDS, $64.44 \%$ respondents thought that safe sexual behavior is the main way to prevent HIV/AIDS. $32.22 \%$ individuals considered it to be by not sharing needles, $28.89 \%$ respondents thought health education regarding AIDS, $26.44 \%$ individuals thought proper maintenance of religious values and $21.44 \%$ considered proper screening as the other measure to prevent HIV/AIDS. $16.11 \%$ respondents had no knowledge about preventive measures. A study done by Prosannajid Sarkar shows that ,respondents thought that HIV/AIDS can be prevented by using condoms during intercourse (49\%), by limiting intercourse to one uninfected person who has no other partner $(51 \%)$ and also abstaining from sexual intercourse $(51 \%)^{14}$.

A study done by Mizanur Rahman, M Kabir shows that, $16.8 \%$ respondents didn't know about preventive measures against AIDS. $65.3 \%$ of the people considered that the preventive measure is to avoid sexual intercourse with multiple partners other preventive measure that they considered were not to have sexual intercourse with risky persons (33.2\%), screening blood before transfusion $(19.6 \%)$ and to avoid used syringe $(13.8 \%)^{13}$.

Another study done by Mizanur Rahman shows 30\% respondents didn't know about the preventive measures against AIDS. Other considered the preventive measure to be avoid promiscuous sex (75\%) followed by using condoms during sexual intercourse (68\%), using sterilized syringe (47\%), avoiding sex with commercial sex workers (46\%), not to have sexual intercourse with multiple sexual partners $(33 \%)$ and also by avoiding homosexual contact $(25 \%)^{13}$. 
Our study revealed that among our target population $61.67 \%$ were sympathetic to AIDS patients where as $30 \%$ respondents had negative attitude towards AIDS patients and 8.33\% respondents were reluctant to give comments .Another study done by Soumya Deb, Sinjita Datta shows that $43.5 \%$ people were sympathetic to HIV/AIDS patients ${ }^{17}$. They felt that it was a matter of bad luck for these who have AIDS, while 32.4\% encouraged their partners to use condoms. It is the natural attitude of mankind to become sympathetic towards any kind of diseased patients.

HIV/AIDS has become a national concern in Bangladesh and the government has already developed a national strategy and an operational plan to address the country's needs. Worldwide experience of HIV/AIDS has suggested that public knowledge on this disease is the most fundamental weapon that can be used to fight against the AIDS pandemic until a vaccine or cure would be developed $^{18}$. In this regard, our study shows that majority of the people $(92.5 \%)$ have knowledge about AIDS. This credit goes to mass media mainly TV. But it is a matter of regret that most of the people have superficial knowledge. They don't have clear conception about modes of transmission, high risk group and prevention. Even some of them possess absurd idea about AIDS. Literacy rate among our respondents was $85.56 \%$. So, it is clear that education always plays an important role in creating awareness among people. It also gives a clear cut idea that proper health education and proper use of mass media can play a major role to inform people about HIV/AIDS. Being an unbiased one, our study may be an excellent source of information for other researchers and also for the concerned authority to take interventions. We can hope that in near future everyone will know about AIDS and none will be infected by this killer disease any more.

\section{Conclusion}

The present study revealed that majority of respondents had gathered information from mass media and they considered that the sexual route is the principal means of spreading HIV/AIDS and the safe sex behaviour is the principal way of prevention of HIV/AIDS and majority of the respondents have the positive and healthy attitude towards HIV/AIDS. So, our study concludes that majority of the respondents have knowledge regarding HIV/AIDS and few have no knowledge and they need information and health education. AIDS is an incurable but preventable disease. Prevention remains the backbone to curb the epidemic in forseeable future.

\section{Reference}

1. Dasgupta S. Halt and Reverse the HIV Epidemic: Millenium Development Goal and NACP III. India Journal of Public Health. 2007; Vol 51: No. 1. p.3- 6.

2. Khosla N. HIV/AIDS Interventions in Bangladesh: What can application of social exclusion framework tell us. J HEALTH POPUL NUTR,2009; Vol 27 (4): p. 587-97.

3. Sarkar K, Das S, Pal R, Bal P, Mudhusudan P, Chakraborti S. HIV infection and host genetic mutation among injecting drug users of Northeastern states of India. J HEALTH POPUL NUTR. 2010; Vol 28 (2) .

4. Kiene SI, Bateganya M, Wanyenze R, Lule $\mathrm{H}$, Nantaba H, Stein MD. Initial outcomes of provider initiated routine HIV testing and counseling during outpatient care at a rural Ugandan hospital: Risk sexual behavior partner, HIV Testing Disclosure and HIV care seeking. AIDS Patient Care and STDs. 2010; Vol 24(2).p34-7

5. Wong LP, Chin CK, Low WY, Jaffar N. HIV/AIDS related knowledge among Malaysian young adults: finding from a nationwide survey. Medscape Journal of medicine. 2008; Vol 10 (6).

6. Chen J, Shengli C, Choe MK. Who has correct information and knowledge about HIV/AIDS in China. Asia-Pacific population journal. December,2003; Vol 18: No. 4. 
7. Boyce W. Cote the influence of HIV/AIDS on community based rehabiltation in Daressalam, Tanzania. ASIA-Pacific disability rehabilitation Journal. 2009; Vol 20: No.1. p.52-6.

8. Takahashi K, Sunthan S, Chomroeun L, Rathmuny H. The effectiveness of HIV/AIDS awareness intervention in a rural area of Cambodia : illiteracy, mobility, sexual behavior and HIV/AIDS. Tropical Medicine \& Health. 2009; Vol 37: No.3. p.109-14. 9. Rahman MS, Rahman ML. Media and education play a tremendous role in mounting AIDS awareness among married couples in Bangladesh. AIDS Research and therapy 2007; Vol 4:10.

10. DGHS Strategic Plan of the National AIDS Programme of Bangladesh AIDS Prevention and Conrol Programme. Directorate General of Health Services, Ministry of Health and Family Welfare, Government of the People's Republic of Bangladesh, Dhaka (2000).

11. Yasmin N, Rouf SF, Hossain ME, Iqubal KF. Knowledge on HIV/AIDS among students of higher secondary college in urban and rural Bangladesh; MPH Programme. Department of Public Health, Dhanmondi, Dhaka-1205, Bangladesh and Department of Environmental Science, States University of Bangladesh, 77 Satmasjid Road Dhanmondi, Dhaka-1205, Bangladesh.

12. Sarkar P. Knowledge and prevention of HIV/AIDS in Bangladesh: Evidence from Bangladesh demographic and health survey, 2007. Journal of AIDS and HIV/Research.2010; 2(1): p. 01-07.
13. Rahman MM, Kabir M, Shahidullah M. Knowledge of AIDS and condom as a preventive measuse against AIDS among married males and factors influencing it in Bangladesh. Kathmondu University Medical Journal. 2007; Vol 5: No.3. Issue 19. p. 364-70.

14. Sarkar P. Informational Knowledge about HIV/AIDS : Bangladesh context. International Journal of Molecular Medicine and advance science. 2009; vol 5: issue 1. p.10- 4.

15. Deji OF, Enuenwemoa C. Assessment of the awareness of HIV/AIDS among the rural dwellers in the zone of Osun state. Nigeria. J. soc.sci. 2005. Vol 10(3): p. 181-4.

16. Rahman MM, Kibr M. Shahidullah M. Adolescent knowledge and awareness about AIDS /HIV and factors affect in them in Bangladesh. J. Ayub Medical college. Abbottabad, 2009; Vol 21(3): p.3-6. http:www.allvocies.com/contributged-news/7687003-vi deo-hiv-stigma 4 years old was made to stay with animals.

17. Deb S, Dutta S, Dasgupta A, Biswas B. Sexual Practice and Perception of HIV/AIDS amongst men who have Sex With Men in Kolkata. Indian journal of community medicine.2009; Vol 34: p. 206-11

18. Maimaiti N, Shamusuddin K, Abdurahim A, Tohti N. Knowledges attitude and practices regarding HIV/AIDS among University Students in Xinjiang. Global Journal of Health Science.2010; Vol 2(2): p. 51-6. 